Article

\title{
Cocoa Shell as a Step Forward to Functional Chocolates-Bioactive Components in Chocolates with Different Composition
}

\author{
Veronika Barišić ${ }^{1} \oplus$, Milica Cvijetić Stokanović ${ }^{1}$, Ivana Flanjak ${ }^{1, *} \oplus$, Kristina Doko ${ }^{2}$, \\ Antun Jozinović ${ }^{1}{ }^{1}$, Jurislav Babić ${ }^{1}{ }^{\infty}$, Drago Šubarić ${ }^{1}$, Borislav Miličević ${ }^{1,3}$, Ines Cindrić 4 \\ and Đurđica Ačkar ${ }^{1}$ (D) \\ 1 Faculty of Food Technology Osijek, Josip Juraj Strossmayer University of Osijek, Franje Kuhača 18, \\ 31000 Osijek, Croatia; veronika.barisic@ptfos.hr (V.B.); milica.cvijetic@ptfos.hr (M.C.S.); \\ antun.jozinovic@ptfos.hr (A.J.); jurislav.babic@ptfos.hr (J.B.); drago.subaric@ptfos.hr (D.Š.); \\ bmilicevic@ptfos.hr (B.M.); dackar@ptfos.hr (Đ.A.) \\ 2 Federal Agro Mediterranean Institute, Biskupa Čule 10, 88000 Mostar, Bosnia and Herzegovina; \\ kristina.skender@gmail.com \\ 3 Department of Agriculture, Polytechnic in Požega, Vukovarska 17, 34000 Požega, Croatia \\ 4 Department of Food Technology, Karlovac University of Applied Sciences, Trg J.J. Strossmayera 9, \\ 47000 Karlovac, Croatia; icindric@vuka.hr \\ * Correspondence: iflanjak@ptfos.hr
}

Received: 9 November 2020; Accepted: 17 November 2020; Published: 23 November 2020

\begin{abstract}
Chocolate is considered as both caloric and functional food. Its nutritional properties may be improved by addition of fiber; however, this may reduce polyphenols content. The aim of this research was to determine the influence of cocoa shell addition (as a source of fiber) and its combination with different ingredients (cocoa butter equivalents (CBE), emulsifiers, dairy ingredients) on polyphenols of dark and milk chocolates. Total polyphenol (TPC) and total flavonoid (TFC) contents were determined spectrophotometrically, identification and quantification of individual compounds by high pressure liquid chromatography and antioxidant capacity by ferric reducing antioxidant power (FRAP) assay. Results showed that even though addition of cocoa shell to chocolate results in reduced contents of TPC, TFC, and individual compounds, it is not significant compared to ones reported by other authors for commercial chocolates. Other ingredients influence determined values for all investigated parameters; however, additional research is needed to reveal exact mechanisms and implications.
\end{abstract}

Keywords: dark chocolate; milk chocolate; cocoa shell; CBE; dairy ingredients; polyphenol; flavonoid

\section{Introduction}

Chocolate is among the most popular foods worldwide. Regardless of age, ethnicity, social status, health, people have been thriving on it since ancient times. It has evolved from drink to food and transformed from exclusivity to staple food. Along with this transition, the contribution of chocolate to total calorie intake has become an issue, but the beneficial effects of cocoa have emerged as well. To this day, chocolate is considered both as a preferred and unwanted food at the same time. Industry and research communities are seeking solutions to reduce the unwanted characteristics of chocolate (e.g., high energy and sugar content) $[1,2]$ and to improve its polyphenol content $[3,4]$, since this is the major positive characteristic of chocolate [5-7].

The aim of this research, however, is to explore the potential of usage of cocoa shell in chocolate production. This is the part of the cocoa bean that is discarded during production, rich in fiber and containing polyphenols of similar profile to cocoa cotyledons and could be used as a source of 
fiber without major impact on the polyphenolic profile. The main reason why it is not normally used in chocolate production lies in the fact that it causes problems with particle size reduction in traditional processes. This is why legislation in European countries used to limit its content to $5 \%$ in cocoa liquor [8]. However, current legislation does not limit its content since technology has evolved, and reuse of food industry by-products in food production is being encouraged. This paper focuses on research into the profile of bioactive components in chocolate with and without cocoa shell, aiming to determine whether replacement of part of the cocoa liquor with the shell would influence these properties. In addition, combinations of cocoa shell with different ingredients, normally used in chocolate production, were investigated as well in order to reveal if there are limitations regarding its use from the aspect of bioactive compounds.

\section{Results and Discussion}

Cocoa shell is being recognized as a valuable raw material in food production as a source of polyphenols [9], fiber [10] or as an antimicrobial agent [11]. Since it is a part of the cocoa bean, one of the major chocolate ingredients, it makes sense to use it in chocolate production. The main ingredient introduced with it into the product is dietary fiber, making up approximately 39-66 g/100 g of the shell [12]. However, the main beneficial chocolate ingredients are polyphenols, with proven health effects, as established by EFSA [6,7] and this should not be disregarded when introducing new ingredients into chocolate.

Total phenolic content (TPC) in chocolates analyzed in this research is presented in Table 1. It ranged from $0.73 \mathrm{mg} \mathrm{GAE} / \mathrm{g}$ of defatted sample to $1.52 \mathrm{mg} \mathrm{GAE} / \mathrm{g}$ of defatted sample for milk chocolates, and from $2.41 \mathrm{mg} \mathrm{GAE} / \mathrm{g}$ of defatted sample to $3.61 \mathrm{mg} \mathrm{GAE} / \mathrm{g}$ of defatted sample for dark chocolates, as determined by modified Folin-Ciocalteau method. The addition of cocoa shell reduced TPC, with more pronounced effect as cocoa shell content increased from $5 \%$ to $15 \%$ in dark chocolate; however, TPC in all analyzed samples was larger than reported by Roda and Lambri [13] for dark (2.12 mg GAE/g of defatted sample) and milk (0.64 mg GAE/g of defatted sample) chocolate. Belščak-Cvitanović et al. [14] reported TPC content of approximately 3.5-5.5 mg GAE/g of defatted sample for milk chocolate and approximately 7.5-12 mg GAE/g of defatted sample for dark chocolate. Godočikova et al. [15] reported TPC values of 4.83-23.58 g GAE $/ \mathrm{kg}$ of defatted sample. In both these researches the standard Folin-Ciocalteu method was applied, corresponding to our results presented as TPC1 in Table 2, which ranged from 1.70 to $3.63 \mathrm{mg}$ GAE/g of defatted sample for milk and 7.54-12.71 mg GAE/g of defatted sample for dark chocolates. It has to be emphasized that these results are overestimated, because when the standard Folin-Ciocalteu method is used, sugars also interact with the Folin-Ciocalteu reagent unlike in the modified method performed in acidic conditions [16].

Total flavonoid content (TFC) in our research ranged from 4.58 to $6.78 \mu \mathrm{mol} \mathrm{CE} / \mathrm{g}$ of defatted sample for milk and 9.65-24.62 $\mu \mathrm{mol} \mathrm{CE/g}$ of defatted sample for dark chocolates, with decreasing values as cocoa shell content increased both for milk and dark chocolates. These results are in accordance with results for commercial chocolates reported by Todorović et al. [17], with average TFC content of $5.4 \pm 0.8 \mu \mathrm{mol} \mathrm{CE} / \mathrm{g}$ of defatted sample for milk and $19.1 \pm 5.3 \mu \mathrm{mol} \mathrm{CE} / \mathrm{g}$ of defatted sample for dark chocolates.

Determined values for TPC and TFC did not only depend on the amount of added cocoa shell, but on other ingredients as well, revealing very complex interactions of polyphenols with other components, for example, carbohydrates, proteins and fats. 
Table 1. Total phenolic (TPC1 and TPC2) and flavonoid (TFC) content and antioxidant capacity (FRAP) of analyzed chocolate samples (average \pm standard deviation).

\begin{tabular}{ccccc}
\hline \multirow{2}{*}{ Sample } & TPC1 & TPC2 & TFC & FRAP Value \\
\cline { 2 - 5 } & mg GAE/g & mg GAE/g & $\mu$ mol CE/g & $\mu$ mol Fe(II)/g \\
\hline MC1 & $3.63 \pm 0.22$ & $1.52 \pm 0.02$ & $6.78 \pm 0.04$ & $33.96 \pm 0.25$ \\
MC2 & $2.61 \pm 0.32$ & $1.07 \pm 0.13$ & $5.72 \pm 0.10$ & $31.46 \pm 0.31$ \\
MC3 & $3.18 \pm 0.07$ & $1.37 \pm 0.09$ & $4.58 \pm 0.21$ & $27.10 \pm 0.08$ \\
MC4 & $2.92 \pm 0.07$ & $1.22 \pm 0.05$ & $5.11 \pm 0.03$ & $28.08 \pm 1.10$ \\
MC5 & $2.35 \pm 0.17$ & $1.05 \pm 0.04$ & $4.94 \pm 0.06$ & $25.17 \pm 0.35$ \\
MC6 & $2.78 \pm 0.14$ & $1.12 \pm 0.06$ & $5.05 \pm 0.06$ & $24.67 \pm 0.71$ \\
MC7 & $2.71 \pm 0.08$ & $1.12 \pm 0.06$ & $5.21 \pm 0.05$ & $26.85 \pm 0.73$ \\
MC8 & $3.09 \pm 0.08$ & $1.28 \pm 0.04$ & $5.72 \pm 0.15$ & $30.86 \pm 0.25$ \\
MC9 & $1.70 \pm 0.23$ & $0.73 \pm 0.07$ & $4.62 \pm 0.06$ & $27.04 \pm 0.87$ \\
DC1 & $12.71 \pm 0.11$ & $3.61 \pm 0.04$ & $24.62 \pm 0.48$ & $108.53 \pm 2.23$ \\
DC2 & $10.86 \pm 0.09$ & $3.33 \pm 0.04$ & $18.25 \pm 0.27$ & $110.23 \pm 0.82$ \\
DC3 & $8.95 \pm 0.44$ & $2.85 \pm 0.07$ & $15.22 \pm 0.30$ & $90.80 \pm 0.50$ \\
DC4 & $8.87 \pm 0.61$ & $2.70 \pm 0.16$ & $11.74 \pm 0.48$ & $75.04 \pm 0.98$ \\
DC5 & $8.84 \pm 0.28$ & $2.63 \pm 0.02$ & $12.18 \pm 0.17$ & $61.26 \pm 1.03$ \\
DC6 & $7.82 \pm 0.14$ & $2.41 \pm 0.04$ & $12.60 \pm 0.34$ & $74.92 \pm 0.90$ \\
DC7 & $8.57 \pm 0.19$ & $2.72 \pm 0.11$ & $10.99 \pm 0.13$ & $77.37 \pm 0.80$ \\
DC8 & $10.68 \pm 0.50$ & $3.20 \pm 0.04$ & $13.80 \pm 0.21$ & $53.10 \pm 0.24$ \\
DC9 & $7.94 \pm 0.11$ & $2.71 \pm 0.05$ & $13.24 \pm 0.36$ & $53.47 \pm 0.21$ \\
DC10 & $7.54 \pm 0.40$ & $2.43 \pm 0.14$ & $9.65 \pm 0.63$ & $50.65 \pm 0.72$ \\
\hline
\end{tabular}

When part of the milk powder was replaced with whey (sample MC4 compared to MC3), determined TPC content decreased (from 1.37 to $1.22 \mathrm{mg} \mathrm{GAE} / \mathrm{g}$ of defatted sample), while TFC content increased (from 4.58 to $5.11 \mathrm{mg} \mathrm{GAE} / \mathrm{g}$ of defatted sample). Urbanska et al. [18] associated the decrease of polyphenol content to increase of protein content in different milk powders, due to formation of protein micelles entrapping polyphenolic compounds, making them inaccessible. However, the type of protein also makes a difference. Jakobek [19] summarized interactions of polyphenols with proteins, fats and carbohydrates, showing high affinity of (+)-catechin, (-)-epicatechin, (-)-epicatechin gallate and (-)-epigallocatechin gallate for hydrophobic and hydrophilic bonding with B-lactoglobulin, with higher affinity of heat-treated protein (which is the case in production of whey powder). Hence, lower contents of (+)-catechin, (-)-epicatechin and (-)-epicatechin gallate were determined in milk chocolate produced with whey powder (Table 2). Shpigelman et al. [20] reported that heat (normally applied during production of whey powder) causes unfolding of $\$$-lactoglobulin, exposing inner parts of protein. These inner parts react with polyphenols via hydrophobic interaction and H-bonding, forming microfibrillar structures. Furthermore, El-Messery et al. [21] reported that the affinity of coffee polyphenols followed the order: skim milk $<$ acid casein $<\alpha$-casein $<\beta$-casein $<$ whey protein isolate $<\alpha$-lactoglobulin, and Urbanska et al. [18] reported lower contents of polyphenols in milk chocolates produced with milk containing higher levels of proteins, supporting the trend observed in our research. 
Table 2. The content of methylxanthines and phenolic components in analyzed chocolate samples (average \pm standard deviation).

\begin{tabular}{|c|c|c|c|c|c|c|c|c|}
\hline \multirow{2}{*}{ Sample } & \multicolumn{8}{|c|}{ Bioactive Component (mg/g) } \\
\hline & TEO & CAF & CAT & EPI & EPG & GA & CA & $p$-CA \\
\hline MC1 & $3.198 \pm 0.139$ & $0.339 \pm 0.028$ & $0.237 \pm 0.019$ & $0.242 \pm 0.019$ & $0.215 \pm 0.018$ & $0.014 \pm 0.001$ & $0.004 \pm 0.001$ & $0.014 \pm 0.000$ \\
\hline MC2 & $2.799 \pm 0.171$ & $0.287 \pm 0.024$ & $0.165 \pm 0.012$ & $0.171 \pm 0.012$ & $0.338 \pm 0.040$ & $0.011 \pm 0.001$ & $0.002 \pm 0.000$ & $0.014 \pm 0.000$ \\
\hline MC3 & $3.056 \pm 0.009$ & $0.338 \pm 0.004$ & $0.183 \pm 0.003$ & $0.184 \pm 0.002$ & $0.410 \pm 0.040$ & $0.011 \pm 0.000$ & $0.004 \pm 0.000$ & $0.013 \pm 0.001$ \\
\hline MC4 & $2.932 \pm 0.030$ & $0.304 \pm 0.003$ & $0.167 \pm 0.002$ & $0.173 \pm 0.002$ & $0.364 \pm 0.029$ & $0.014 \pm 0.001$ & $0.004 \pm 0.000$ & $0.009 \pm 0.005$ \\
\hline MC5 & $2.843 \pm 0.041$ & $0.270 \pm 0.004$ & $0.149 \pm 0.004$ & $0.154 \pm 0.004$ & $0.182 \pm 0.003$ & $0.010 \pm 0.000$ & $0.002 \pm 0.000$ & $0.013 \pm 0.000$ \\
\hline MC6 & $2.868 \pm 0.057$ & $0.288 \pm 0.004$ & $0.162 \pm 0.004$ & $0.166 \pm 0.005$ & $0.185 \pm 0.024$ & $0.011 \pm 0.000$ & $0.003 \pm 0.001$ & $0.014 \pm 0.002$ \\
\hline MC7 & $2.992 \pm 0.071$ & $0.311 \pm 0.010$ & $0.167 \pm 0.007$ & $0.176 \pm 0.005$ & $0.304 \pm 0.063$ & $0.010 \pm 0.000$ & $0.004 \pm 0.000$ & $0.012 \pm 0.000$ \\
\hline MC8 & $3.029 \pm 0.068$ & $0.327 \pm 0.015$ & $0.202 \pm 0.009$ & $0.204 \pm 0.009$ & $0.244 \pm 0.021$ & $0.010 \pm 0.001$ & $0.004 \pm 0.000$ & $0.014 \pm 0.001$ \\
\hline MC9 & $2.146 \pm 0.100$ & $0.211 \pm 0.011$ & $0.113 \pm 0.006$ & $0.120 \pm 0.008$ & $0.201 \pm 0.016$ & $0.005 \pm 0.001$ & $0.000 \pm 0.000$ & $0.013 \pm 0.001$ \\
\hline DC1 & $4.819 \pm 0.082$ & $0.887 \pm 0.079$ & $0.667 \pm 0.065$ & $0.701 \pm 0.073$ & $0.272 \pm 0.033$ & $0.042 \pm 0.005$ & $0.032 \pm 0.005$ & $0.024 \pm 0.004$ \\
\hline DC2 & $4.621 \pm 0.042$ & $0.856 \pm 0.012$ & $0.596 \pm 0.008$ & $0.613 \pm 0.015$ & $0.346 \pm 0.013$ & $0.041 \pm 0.001$ & $0.028 \pm 0.002$ & $0.023 \pm 0.001$ \\
\hline DC3 & $4.326 \pm 0.016$ & $0.738 \pm 0.045$ & $0.464 \pm 0.030$ & $0.471 \pm 0.032$ & $0.295 \pm 0.029$ & $0.039 \pm 0.002$ & $0.021 \pm 0.002$ & $0.017 \pm 0.000$ \\
\hline DC4 & $4.171 \pm 0.066$ & $0.653 \pm 0.026$ & $0.379 \pm 0.027$ & $0.384 \pm 0.019$ & $0.289 \pm 0.019$ & $0.035 \pm 0.001$ & $0.019 \pm 0.001$ & $0.018 \pm 0.001$ \\
\hline DC5 & $4.221 \pm 0.023$ & $0.669 \pm 0.008$ & $0.410 \pm 0.015$ & $0.417 \pm 0.005$ & $0.273 \pm 0.016$ & $0.039 \pm 0.004$ & $0.024 \pm 0.001$ & $0.020 \pm 0.000$ \\
\hline DC6 & $4.043 \pm 0.013$ & $0.614 \pm 0.015$ & $0.355 \pm 0.008$ & $0.362 \pm 0.007$ & $0.237 \pm 0.006$ & $0.032 \pm 0.001$ & $0.017 \pm 0.000$ & $0.017 \pm 0.000$ \\
\hline DC7 & $4.103 \pm 0.071$ & $0.690 \pm 0.007$ & $0.394 \pm 0.006$ & $0.404 \pm 0.012$ & $0.335 \pm 0.016$ & $0.039 \pm 0.001$ & $0.020 \pm 0.002$ & $0.018 \pm 0.001$ \\
\hline DC8 & $4.568 \pm 0.061$ & $0.812 \pm 0.031$ & $0.553 \pm 0.018$ & $0.561 \pm 0.029$ & $0.431 \pm 0.036$ & $0.033 \pm 0.001$ & $0.023 \pm 0.003$ & $0.021 \pm 0.005$ \\
\hline DC9 & $4.665 \pm 0.528$ & $0.683 \pm 0.032$ & $0.393 \pm 0.027$ & $0.473 \pm 0.050$ & $0.382 \pm 0.044$ & $0.030 \pm 0.007$ & $0.027 \pm 0.010$ & $0.022 \pm 0.010$ \\
\hline DC10 & $3.771 \pm 0.106$ & $0.562 \pm 0.036$ & $0.319 \pm 0.021$ & $0.280 \pm 0.020$ & $0.403 \pm 0.037$ & $0.019 \pm 0.002$ & $0.000 \pm 0.000$ & $0.013 \pm 0.000$ \\
\hline
\end{tabular}

TEO, theobromine; CAF, caffeine; CAT-(+), catechin; EPI-(-), epicatechin; EPG-(-), epicatechin gallate; GA, gallic acid; CA, caffeic acid; $p$-CA, $p$-coumaric acid. 
Fat type also influences determined values for polyphenol content. In this research, $5 \%$ of cocoa butter was replaced with palm or coconut oil. In dark chocolates, TPC followed the order: sample without cocoa butter equivalents $(\mathrm{CBE})(\mathrm{DC} 4)>$ sample with palm oil (DC5) $>$ sample with coconut oil (DC6), while in milk chocolates the order was: sample without CBE (MC3) > sample with coconut oil (MC 6) > sample with palm oil (MC5) (Table 1). A possible explanation could be that part of polyphenols was extracted from samples together with fat during defatting. Jakobek [19] reported that lipids can "capture" polyphenols. The main difference between cocoa butter, palm and coconut oil is in fatty acid composition. While in cocoa butter C18:0 and C18:1 prevail, in palm oil C16:0 is the dominant fatty acid and in coconut oil MCFAs are present, with C12:0 as the most represented [22], which influences polarity of fats. Yara-Varon et al. [23] established vegetable oils, such as corn, olive, palm and refined sunflower oil, as potential green solvents for extraction of polyphenols, as a single solvent, mixed with organic solvents, or combined with different technologies (microwave, ultrasound, supercritical CO2 extraction). Li et al. [24] used different types of oils for extraction of polyphenols from olive leaves. Although castor oil, categorized as polar, had the best performance, good results were achieved with unrefined oils as well. Apparently, minor compounds in oils also affect solubility of polyphenols. Contents of individual polyphenolic compounds followed the order: sample with palm oil (DC5) $>$ sample without CBE (DC4) > sample with coconut oil (DC6) for dark chocolates and sample without CBEs (MC3) > sample with coconut oil (MC6) > sample with palm oil (MC5) for milk chocolates. Apparently, polarity of oil, as well as milk components, influences interactions of fat with polyphenols. According to Li et al. [24], emulsifiers improve extraction of polyphenols with fats. In our research, lecithin was used as a standard emulsifier and part of it was replaced with PGPR (samples MC7 and DC7). This resulted in reduced contents of TPC, CAT, EPI and EPG in milk chocolate, however, the opposite effect was observed for dark chocolate, again implying that milk components interfere with these reactions.

TFC content followed the order: sample with coconut oil $>$ sample with palm oil $>$ sample without CBE. Apparently, solubility of individual compounds in oil and polarity of oils influences the obtained results.

Another component influencing polyphenol behavior in food systems is fiber. In our previous researches we treated cocoa shell with HVED and explored its influence on polyphenols [25] and fiber [26]. HVED reduced contents of all analyzed polyphenolic components and increased content of insoluble fiber, which was reflected in properties of chocolates in this research. Both TPC and TFC were lower in dark chocolates produced with HVED treated cocoa shell, due to initial lower contents (Table 1). This trend, however, is not clearly visible in milk chocolates, where TFC was lower (or equal) in chocolates with untreated cocoa shell. Additionally, when observing particular compounds, correlation between fiber contents and contents of polyphenolic compounds cannot be drawn. In addition to fiber content, porosity and surface properties of fiber, as well as molecular weight of polyphenols and polyphenol-protein complexes influence these interactions [19]. After HVED treatment, both oil- and water-binding capacities of cocoa shell increased [26], indicating that HVED could result in a more porous structure of fiber. The pores could entrap polyphenols not only from cocoa shell, but from cocoa mass as well, making them inaccessible for extraction and determination. Another aspect that has to be taken into consideration is particle size and total surface area for interactions of fiber and polyphenols. Although a specific fraction of cocoa shell was taken into chocolate production, where particle size did not differ between untreated and HVED treated cocoa shell, during milling and conching in ball mill particles were reduced to different extents, depending on chocolate composition. Although parallels cannot be drawn between contents of polyphenolic compounds and specific surface area of chocolate particles (results not shown), it could contribute to complexity of interactions and final availability of polyphenols.

Introducing milk ingredients brings about even more complexity to the system. When $5 \%$ of cocoa shell was used (samples MC3 and MC9), addition of shell treated with HVED resulted in lower content of analyzed individual compounds, however, when $2.5 \%$ of the shell was used (samples 
MC2 and MC8), this trend was not observed for all compounds. Specifically, contents of (+)-catechin, $(-)$-epicatechin and caffeic acid were lower in samples with untreated shell, although the shell itself contained higher proportions, as reported earlier [25]. (-)-Epicatechin is well described in regarding antioxidant properties and reactions involved [27], with more pronounced activity in non-polar media, such as fats (hence, chocolate is a product with high cocoa butter content) [24]. It even interferes with Maillard reactions, quenching sugar fragmentation products [28], could undergo epimerization reactions and finally condensation into tannins also interact with proteins [26]. (+)-Catechin is very similar in properties to (-)-epicatechin and this is the main reason why they show similar behavior in this research as well.

(-)-Epicatechin gallate (EPG) is the compound where it is easiest to see that influence of different ingredients on polyphenol content and availability cannot be easily predicted. Its content in cocoa mass was $0.124 \pm 0.007 \mathrm{mg} / \mathrm{g}, 0.030 \pm 0.002 \mathrm{mg} / \mathrm{g}$ in untreated cocoa shell and $0.009 \mathrm{mg} / \mathrm{g}$ in treated cocoa shell. It is expected that partial replacement of cocoa mass with shell would result in a decrease of EPG in chocolate, but this was not the case. In dark chocolates, EPG content followed the order: DC8 $>$ DC10 > DC9 > DC2 > DC7 > DC3 > DC4 > DC5 > DC1 > DC6 and in milk chocolates the order was: MC3 $>$ MC4 $>$ MC2 $>$ MC7 $>$ MC8 $>$ MC1 $>$ MC9 $>$ MC6 $>$ MC5. EPG is the largest polyphenol of the analyzed molecules with molecular mass of $442.37 \mathrm{~g} / \mathrm{mol}$ (compared to $290.27 \mathrm{~g} / \mathrm{mol}$ for (-)-epicatechin and (+)-catechin, $180.16 \mathrm{~g} / \mathrm{mol}$ for caffeic acid and $164.16 \mathrm{~g} / \mathrm{mol}$ for $p$-coumaric acid) and the largest number of active sites for interactions with other compounds. It could be trapped within the fiber matrix in cocoa shell and liberated with subsequent milling during chocolate production, or chemically linked to fiber in the shell with disturbance of chemical bonding with increase of hydrophobic conditions in chocolate due to addition of cocoa butter and other fats, or formed through interactions of monomeric compounds, or in combination.

Differences in chemical compositions of chocolates are reflected in their antioxidant properties analyzed by FRAP assay (Table 1). Due to so-called dilution factors, milk chocolates had lower antioxidant capacity. Addition of cocoa shell resulted in a decrease of antioxidant capacity of milk chocolates; however, HVED treatment of cocoa shell prior to addition did not have an influence on the determined values. In dark chocolates, however, the difference between chocolates with HVED treated shell (DC8, 9 and 10) and chocolates without the shell (DC1) and with untreated shell (DC2, 3 and 4 ) was remarkable, with $30 \%-50 \%$ reduction of determined values. This, however, did not correspond to determined TPC values, but may be linked to the reduction of HMF (5-(hydroxymethyl)furfural) in cocoa shell after HVED treatment determined in our previous research [29]. Although the FRAP assay is considered as a cheap and fast method giving reliable insight into antioxidant capacity, it has been established that different organic and inorganic compounds interfere with the reaction [30,31] and Turkut et al. [32] reported strong positive correlation between HMF content in honey and its antioxidant capacity determined by FRAP. Additionally, the reaction time in assay is too short for complete reaction of all compounds (e.g., caffeic acid) and this could have influenced results as well [33]. Other components (type of CBE, emulsifier, type of dairy protein) did not significantly influence results of antioxidant capacity.

Contents of theobromine in present research were $2.146-3.198 \mathrm{mg} / \mathrm{g}$ in milk chocolates and $3.771-4.819 \mathrm{mg} / \mathrm{g}$ in dark chocolates. In both cases, the highest content was observed in control samples, while the lowest in samples with the largest contents of HVED treated cocoa shell. Typical chromatograms of dark chocolate sample (DC1) and dark chocolate with cocoa shell (DC10) are presented in Figure 1. Belščak et al. [14] reported significantly higher values of theobromine content both in milk $(3.405 \mathrm{mg} / \mathrm{g})$ and in dark chocolates $(8.514 \mathrm{mg} / \mathrm{g})$. Batista et al. [34] reported 0.50-12.00 g theobromine/ $\mathrm{kg}$ chocolate with 70\% cocoa, depending on cocoa variety and fermentation conditions, and Bordiga et al. [35] reported values $6.14-8.26 \mathrm{mg} / \mathrm{g}$ for dark chocolates. It is evident that contents of theobromine in our research were lower than reported by others. This could be due to differences in raw materials (e.g., cocoa mass) or due to differences in extraction and analyses 
conditions. The addition of cocoa shell resulted in reductions of theobromine content, but other investigated ingredients did not affect it significantly.

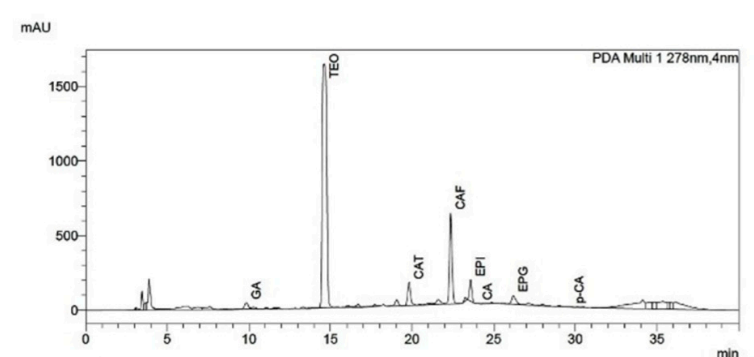

a)

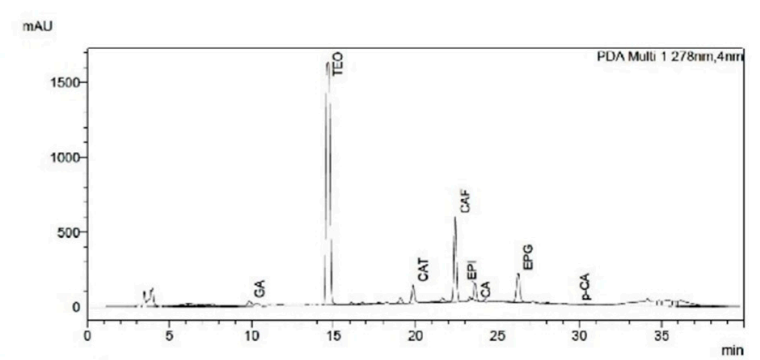

b)

Figure 1. HPLC chromatograms of identified bioactive components in dark chocolate sample (a) and dark chocolate with cocoa shell (b) recorded at $278 \mathrm{~nm}$. Peaks: GA (gallic acid), TEO (theobromine), CAT ((+)-catechin), CAF (caffeine), EPI ((-)-epicatechin), CA (caffeic acid), EPG ((-)-epicatechin gallate) and $p$-CA ( $p$-coumaric acid).

Contents of caffeine in present research were $0.211-0.339 \mathrm{mg} / \mathrm{g}$ for milk and $0.562-0.887 \mathrm{mg} / \mathrm{g}$ for dark chocolates. Again, it may be observed that the addition of cocoa shell reduced the contents of caffeine, while CBE addition had an influence on its content in milk chocolates. Furthermore, these values are below the ones reported by Belščak-Cvitanović et al. [4] ( $0.551 \mathrm{mg} / \mathrm{g}$ for milk and $0.925 \mathrm{mg} / \mathrm{g}$ for dark chocolate), but above the values reported for dark chocolates by Bordiga et al. [35] (0.164-0.347 mg/g).

Methylxanthines in cocoa and cocoa products do not only pose health effects through action on adenosine receptors in the central nervous system and boosting concentration, mood and arousal levels, but have an impact on sensory properties of chocolate as well [36], and their contents are important both from the aspect of quality and for functional properties of chocolate.

\section{Materials and Methods}

\subsection{Chemicals}

Hydrochloric acid, n-hexane (HPLC grade) and Folin-Ciocalteu reagent were purchased from Carlo Erba Reagents (Val de Reuil, France), and sodium hydroxide and sodium nitrite from Gram-mol (Zagreb, Croatia), ferric chloride hexahydrate and sodium acetate trihydrate from T.T.T. (Sveta Nedelja, Croatia), and aluminum chloride hexahydrate from Kemika (Zagreb, Croatia). Sodium carbonate was supplied by Panreac Química (Castellar del Vallès, Spain), ferrous sulfate heptahydrate by Acros Organics (Madrid, Spain) and 2,4,6-Tris(2-pyridyl)-s-triazine (TPTZ) by Alfa Aesar (Karlsruhe, Germany). HPLC grade standards of theobromine, caffeine and $(+)$-catechin, (-)-epicatechin gallate, caffeic acid and $p$-coumaric acid, gallic acid and (-)-epicatechin were purchased from Sigma-Aldrich (St. Louis, MO, USA). Methanol (J.T. Baker, Deventer, The Netherlands) and formic acid (Scharlau Chemie, Spain) used for mobile phase preparation were HPLC grade.

\subsection{Chocolate Samples}

Cocoa mass and cocoa butter were purchased from DGF (Paris, France), milk powder from Dukat d.d. (Zagreb, Croatia), whey powder from Vindija d.d. (Varaždin, Croatia), powdered soy lecithin from A.C.E.F. (Fiorenzuola d'Arda, Italy), polyglycerol polyricinoleate (PGPR) from (Azelis, Croatia), palm oil from Rapunzel (Legau, Germany) and coconut oil from Zvijezda d.d. (Zagreb, Croatia).

Dark and milk chocolates were produced in a laboratory ball mill with different amounts of untreated cocoa shell (roasted at $135^{\circ} \mathrm{C}, 55 \mathrm{~min}$ ) and cocoa shell treated with high voltage electrical discharge (HVED) (Table 3). Treated cocoa shell was subjected to $15 \mathrm{kV} / \mathrm{cm}$ of electric field density at concentration of $3 \%$, frequency of $40 \mathrm{~Hz}$ and time of $15 \mathrm{~min}$. Treated shell was frozen at $-80{ }^{\circ} \mathrm{C}$ and freeze-dried (Alpha LCS Plus, Christ, Osterode am Harz, Germany). Untreated and treated cocoa 
shell were milled (M20, IKA, Staufen, Germany) and sieved, after which the portion under $71 \mu \mathrm{m}$ was used in production. For dark chocolates $2.5 \mathrm{~kg}$ of stainless steel balls $(9.525 \mathrm{~mm}$ diameter) were used in production and $3 \mathrm{~kg}$ for milk. Mixing was performed at $60 \mathrm{rpm}$ and temperature was controlled with water bath $\left(55^{\circ} \mathrm{C}\right)$. Dark and milk chocolates without added cocoa shell were mixed for $3 \mathrm{~h}$ and the ones with added shell for $3.5 \mathrm{~h}$ (fats and cocoa shell were added half an hour before other ingredients). Emulsifiers were added one hour before end of mixing, and aroma (vanillin) half an hour before the end of mixing in ball mill. Tempering was carried out by hand and the temper index was measured with a Sollich Tempermeter E3 (Bad Salzuflen, Germany) (desired temper index 4-7). After tempering, chocolates were molded and cooled for $30 \mathrm{~min}$ at $8{ }^{\circ} \mathrm{C}$.

Table 3. Composition of chocolate samples.

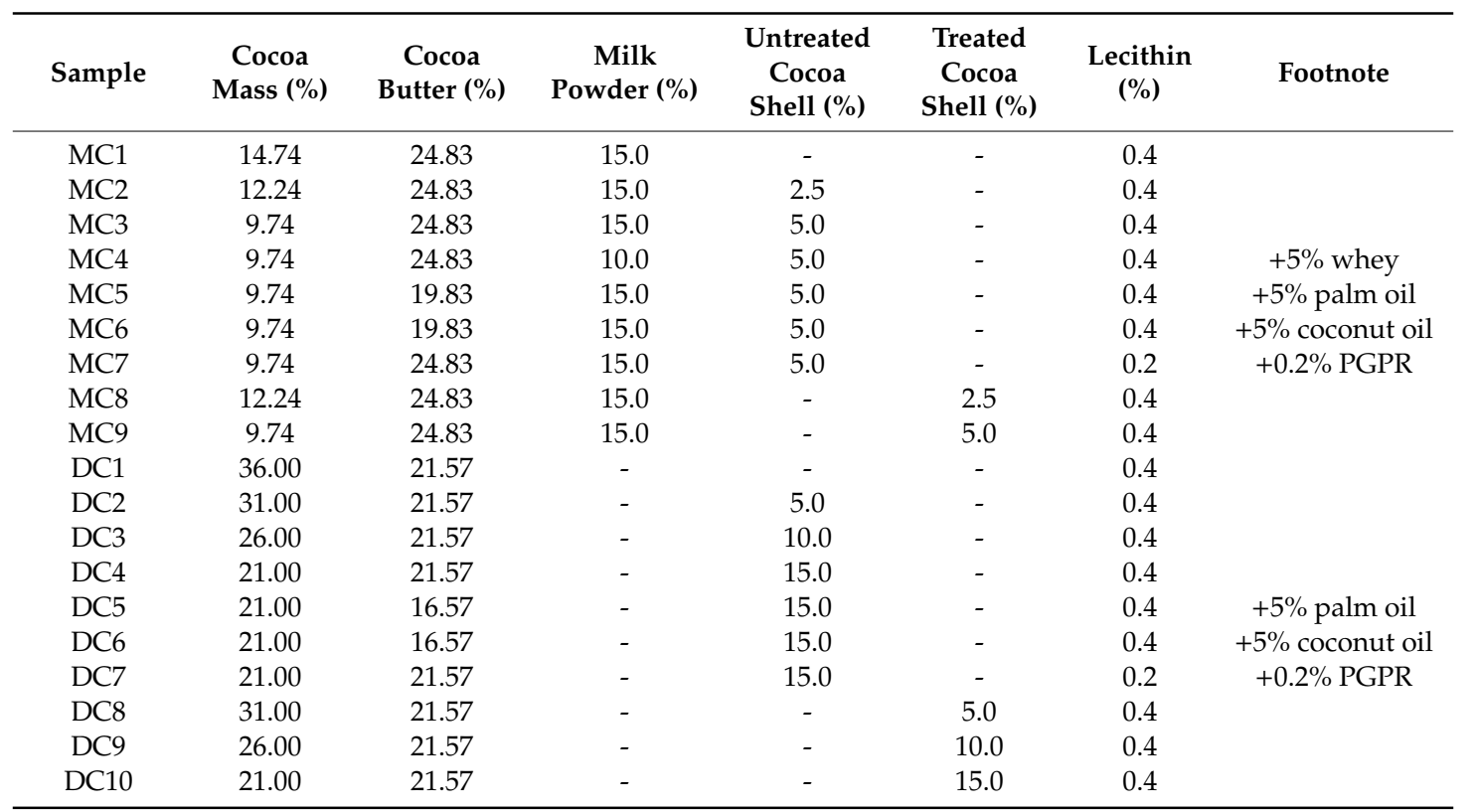

All milk chocolates had $45 \%$ sugar and dark chocolates had $42 \%$ sugar; all chocolates had $0.03 \%$ vanillin. PGPR-polyglycerol polyricinoleate.

\subsection{Extraction of Bioactive Components}

Extraction of bioactive components from chocolate samples was performed according to Adamson et al. [37] and Barišić et al. [25]. Prior to the extraction, chocolates were grated and $3 \mathrm{~g}$ of grated sample was treated three times with $10 \mathrm{~mL}$ of $\mathrm{n}$-hexane to eliminate lipids. The remaining defatted solids were air-dried for $24 \mathrm{~h}$. Afterwards, the extraction procedure of bioactive components was as follows: two grams $( \pm 0.1 \mathrm{~g})$ of defatted chocolate sample was mixed with $5 \mathrm{~mL}$ of $70 \%$ aqueous methanol, sonicated for $30 \mathrm{~min}$, centrifuged for $10 \mathrm{~min}$ at $3000 \mathrm{rpm}$ and the supernatant was decanted into a $10 \mathrm{~mL}$ volumetric flask. The extraction procedure in an ultrasonic bath and centrifugation was repeated once more with the same amount of $70 \%$ aqueous methanol. After combining the extracts, the volumetric flask was filled up to the mark with $70 \%$ aqueous methanol. The obtained extracts were stored in a freezer and filtered through $0.45 \mu \mathrm{m}$ nylon membrane filter before analyses.

\subsection{HPLC Analysis}

Selected methylxanthines and phenolics were identified and quantified as described in our previous paper [25]. The analysis was performed on a Shimadzu HPLC instrument equipped with a LC-20AD quaternary pump (Shimadzu, Kyoto, Japan), a CTO-20AC column oven (Shimadzu, Kyoto, Japan), a SPD-M20A array detector (PDA, Shimadzu, Kyoto, Japan) and a SIL-10AF autosampler (Shimadzu, Kyoto, Japan). Separation of components was performed using an Inertsil ODS-3V column (GL Sciences, Tokyo, Japan) $(250 \times 4.6 \mathrm{~cm}, 5 \mu \mathrm{m}$ particle size). The gradient elution (flow rate 
$0.8 \mathrm{~mL} / \mathrm{min}$ ) was performed using HPLC grade methanol (solvent A) and 1\% formic acid (solvent B). Starting percentage of solvent $\mathrm{A}$ in the mobile phase was $10 \%$, followed by linear increase to $32 \%$ A at $15 \mathrm{~min}, 40 \% \mathrm{~A}$ at $20 \mathrm{~min}$ up to $25 \mathrm{~min}$ and $60 \% \mathrm{~A}$ at $30 \mathrm{~min}$. The injection volume of the sample was $20 \mu \mathrm{L}$, and the column and detector temperatures were $30^{\circ} \mathrm{C}$. Spectrum monitoring was performed in the wavelength range from 200 to $400 \mathrm{~nm}$, while detection of separated components was at $278 \mathrm{~nm}$. Identification of bioactive components was achieved based on the comparison of the retention times and spectrum data with those of the standards while quantification was obtained with the external calibration method. All analyses were repeated three times, and the results expressed as mg of specific bioactive component per $\mathrm{g}$ of defatted chocolate $(\mathrm{mg} / \mathrm{g})$.

\subsection{Total Phenolic Content}

Total phenolic content of chocolate extract was determined by two methods, the original Folin-Ciocalteu method (TPC1) [38] and by modified Folin-Ciocalteu method (TPC2) [16]. All analyses were performed in triplicate.

Total phenolic content (TPC1) was determined as follows: an aliquot $(0.1 \mathrm{~mL})$ of chocolate extract was mixed with $6 \mathrm{~mL}$ of water and $0.5 \mathrm{~mL}$ of Folin-Ciocalteu reagent in the volumetric flask. After $6 \mathrm{~min}$, $1.5 \mathrm{~mL}$ of $20 \% \mathrm{Na}_{2} \mathrm{CO}_{3}$ was added and the flask was filled up with distilled water to final volume $(10 \mathrm{~mL})$. The prepared mixture was left for $2 \mathrm{~h}$ at room temperature in a dark place and the absorbance of final solution was measured at $760 \mathrm{~nm}$ against the blank. The quantification using gallic acid as standard $(0.14-1.0 \mathrm{mg} / \mathrm{mL})$ and the results were expressed as $\mathrm{mg}$ gallic acid equivalents per $\mathrm{g}$ of defatted chocolate (mg GAE/g).

The modified Folin-Ciocalteu method [16] performed under acidic conditions (without addition of $\mathrm{Na}_{2} \mathrm{CO}_{3}$ ) was used to eliminate sugar interference with the Folin-Ciocalteu reagent. Briefly, $0.1 \mathrm{~mL}$ of chocolate extract was mixed with $1 \mathrm{~mL}$ of $10 \%$ Folin-Ciocalteu reagent. After vortexing for $2 \mathrm{~min}$, the mixture was incubated for $20 \mathrm{~min}$ at room temperature in the dark. The absorbance was determined at $750 \mathrm{~nm}$ against the blank. The quantification was carried out using gallic acid as standard $(0.14-0.70 \mathrm{mg} / \mathrm{mL})$ and the results were expressed as $\mathrm{mg}$ gallic acid equivalents per $\mathrm{g}$ of defatted chocolate (mg GAE/g).

\subsection{Total Flavonoid Content}

The determination of total flavonoid content (TFC) was performed according to the Yang et al. [39] with minor modifications. An aliquot of methanolic chocolate extract $(0.125 \mathrm{~mL})$ was mixed with $1.5 \mathrm{~mL}$ of water and $0.15 \mathrm{~mL}$ of $5 \% \mathrm{NaNO}_{2}$. After $5 \mathrm{~min}$ of incubation at room temperature, $0.75 \mathrm{~mL} 2 \%$ $\mathrm{AlCl}_{3} \cdot 6 \mathrm{H}_{2} \mathrm{O}$ was added. After $5 \mathrm{~min}$ of incubation, $1 \mathrm{~mL}$ of $1 \mathrm{M} \mathrm{NaOH}$ was added and the mixture filled with distilled water up to final volume $(5 \mathrm{~mL})$. The absorbance of reaction mixture was measured at $510 \mathrm{~nm}$ against the blank. Total flavonoid content, expressed as $\mu \mathrm{mol}$ catechin equivalents per $\mathrm{g}$ of defatted chocolate ( $\mu \mathrm{mol} \mathrm{CE} / \mathrm{g})$, was calculated from a calibration curve $(0.1-3.5 \mathrm{mM})$ of catechin standard solutions. All measurements were performed in triplicate.

\subsection{FRAP (Ferric Reducing Antioxidant Power) Assay}

For the determination of total antioxidant capacity, the assay described by Benzie and Strain [40] was used. The working FRAP reagent was prepared daily by mixture of $10 \mathrm{mM}$ TPTZ (2,4,6-Tris(2-pyridyl)-s-triazine) solution dissolved in $40 \mathrm{mM} \mathrm{HCl}, 20 \mathrm{mM} \mathrm{FeCl}_{3}$ and $0.3 \mathrm{M}$ acetate buffer solution (pH 3.6) in 1:1:10 ratio. An aliquot of $0.1 \mathrm{~mL}$ diluted chocolate extract was mixed with $1.9 \mathrm{~mL}$ of FRAP reagent, vortexed and incubated at $37^{\circ} \mathrm{C}$ for $4 \mathrm{~min}$. After incubation, the absorbance was measured at $593 \mathrm{~nm}$ against the blank. All measurements were performed in triplicate. Aqueous standard solutions of $\mathrm{FeSO}_{4} \cdot 7 \mathrm{H}_{2} \mathrm{O}(0.1-1 \mathrm{mM})$ were used for calibration curve and the results were expressed as the FRAP

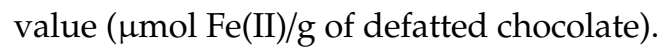




\section{Conclusions}

The research presented in this paper shows that cocoa shell may be used in chocolate production as a source of dietary fiber, without major impact on polyphenol and methylxanthine contents even though it does negligibly reduce the contents of these bioactive compounds. It may be combined with commonly used CBEs and emulsifiers, as well as milk components. It is yet to be revealed exactly how CBEs and different proteins interact with polyphenolic compounds and how these interactions influence bioavailability of the bioactive compounds in chocolates.

Author Contributions: Conceptualization, V.B., I.F. and Đ.A.; methodology, M.C.S.; investigation, V.B., I.F., D.Š. and A.J.; writing—original draft preparation, V.B. and Đ.A.; writing-review and editing, A.J., J.B., B.M. and Đ.A.; visualization, A.J., K.D. and I.C.; funding acquisition, I.C. and Đ.A. All authors have read and agreed to the published version of the manuscript.

Funding: This research was funded in part by the Croatian Science Foundation under the project UIP 2017-05-8709 and as part of the "Atrium of Knowledge" project co-financed by the European Union from the European Regional Development Fund and the Operational Programme Competitiveness and Cohesion 2014-2020. Contract No: KK.01.1.1.02.0005.

Conflicts of Interest: The authors declare no conflict of interest.

\section{References}

1. Aguilar-Villa, C.; Acosta-Otálvaro, E.V.; Rodríguez-Sandoval, E.; Mazo-Rivas, J.C. Sucrose-free milk chocolate manufacture using bulking agents and a non-caloric sweetener. Food Sci. Technol. 2020, 40, 62-67. [CrossRef]

2. Rad, A.H.; Pirouzian, H.R.; Toker, O.S.; Konar, N. Application of simplex lattice mixture design for optimization of sucrose-free milk chocolate produced in a ball mill. LWT 2019, 115, 108435. [CrossRef]

3. Loncarevic, I.; Pajin, B.; Fišteš, A.; Šaponjac, V.T.; Petrović, J.; Jovanovic, P.; Vulic, J.; Zarić, D. Enrichment of white chocolate with blackberry juice encapsulate: Impact on physical properties, sensory characteristics and polyphenol content. LWT 2018, 92, 458-464. [CrossRef]

4. Belščak-Cvitanović, A.; Komes, D.; Benković, M.; Karlović, S.; Hečimović, I.; Ježek, D.; Bauman, I. Innovative formulations of chocolates enriched with plant polyphenols from Rubus idaeus L. leaves and characterization of their physical, bioactive and sensory properties. Food Res. Int. 2012, 48, 820-830. [CrossRef]

5. EFSA. Scientific Opinion on the substantiation of health claims related to cocoa flavanols and protection of lipids from oxidative damage (ID 652, 1372, 1506, 3143), and maintenance of normal blood pressure (ID 1507) pursuant to Article 13(1) of Regulation (EC). EFSA J. 2010, 8, 1792. [CrossRef]

6. EFSA. Scientific Opinion on the substantiation of a health claim related to cocoa flavanols and maintenance of normal endothelium-dependent vasodilation pursuant to Article 13(5) of Regulation (EC) No 1924/2006. EFSA J. 2012, 10, 2809. [CrossRef]

7. EFSA. Scientific Opinion on the modification of the authorisation of a health claim related to cocoa flavanols and maintenance of normal endothelium-dependent vasodilation pursuant to Article 13(5) of Regulation (EC) No 1924/2006 following a request in accordance with Article 19 of Regulation (EC) No 1924/2006. EFSA J. 2014, 12, 3654. [CrossRef]

8. Wood, R. Legal Aspects of chocolate Manufacture. In Beckett's Industrial Chocolate Manufacture and Use, 5th ed.; Beckett, S.T., Fowler, M.S., Ziegler, G.R., Eds.; Wiley Blackwell: Chichester, UK, 2017; pp. 675-694.

9. De Barros, H.E.A.; Natarelli, C.V.L.; Tavares, I.M.D.C.; De Oliveira, A.L.M.; Araújo, A.B.S.; Pereira, J.; Carvalho, E.E.N.; de Barros Vilas Boas, E.V.; Franco, M. Nutritional Clustering of Cookies Developed with Cocoa Shell, Soy, and Green Banana Flours Using Exploratory Methods. Food Bioprocess Technol. 2020, 13, 1566-1578. [CrossRef]

10. Collar, C.; Rosell, C.; Muguerza, B.; Moulay, L. Breadmaking Performance and Keeping Behavior of Cocoa-soluble Fiber-enriched Wheat Breads. Food Sci. Technol. Int. 2009, 15, 79-87. [CrossRef]

11. Kayaputri, I.L.; Djali, M.; Sukri, N.; Fazaryasti, R.H. The antimicrobial effectiveness of cacao shell and cacao husk combination on inhibition of pathogenic bacteria in food products. IOP Conf. Ser. Earth Environ. Sci. 2020, 443, 12077. [CrossRef]

12. Rojo-Poveda, O.; Barbosa-Pereira, L.; Zeppa, G.; Stévigny, C. Cocoa Bean Shell-A By-Product with Nutritional Properties and Biofunctional Potential. Nutrients 2020, 12, 1123. [CrossRef] [PubMed] 
13. Roda, A.; Lambri, M. Changes in Antioxidants and Sensory Properties of Italian Chocolates and Related Ingredients Under Controlled Conditions During an Eighteen-Month Storage Period. Nutrients 2019, 11, 2719. [CrossRef] [PubMed]

14. Belščak, A.; Komes, D.; Horžić, D.; Ganić, K.K.; Karlović, D. Comparative study of commercially available cocoa products in terms of their bioactive composition. Food Res. Int. 2009, 42, 707-716. [CrossRef]

15. Godočikova, L.; Ivanišova, E.; Zagula, G.; Noguera-Artiaga, L.; Carbonell-Barrachina, A.A.; Kowalczewski, P.L.; Kačanina, M. Antioxidant Activities and Volatile Flavor Components of Selected Single-Origin and Blend Chocolates. Molecules 2020, 25, 3648. [CrossRef]

16. Vinson, J.A.; Proch, J.; Bose, P. Determination of quantity and quality of polyphenol antioxidants in foods and beverages. Methods Enzymol. 2001, 335, 103-114. [CrossRef]

17. Todorović, V.; Redovnikovic, I.R.; Todorovic, Z.; Jankovic, G.; Dodevska, M.; Sobajic, S. Polyphenols, methylxanthines, and antioxidant capacity of chocolates produced in Serbia. J. Food Compos. Anal. 2015, 41, 137-143. [CrossRef]

18. Urbańska, B.; Szafrański, T.; Kowalska, H.; Kowalska, J. Study of Polyphenol Content and Antioxidant Properties of Various Mix of Chocolate Milk Masses with Different Protein Content. Antioxidants 2020, 9, 299. [CrossRef]

19. Jakobek, L. Interactions of polyphenols with carbohydrates, lipids and proteins. Food Chem. 2015, 175, 556-567. [CrossRef]

20. Shpigelman, A.; Israeli, G.; Livney, Y.D. Thermally induced protein-polyphenol co-assemblies: Beta lactoglobulinbased nanocomplexes as protective nanovehicles for EGCG. Food Hydrocolloid. 2010, 24, 735-743. [CrossRef]

21. El-Messery, T.M.; Mwafy, E.A.; Mostafa, A.M.; El-Din, H.M.F.; Mwafy, A.; Amarowicz, R.; Ozçelik, B. Spectroscopic studies of the interaction between isolated polyphenols from coffee and the milk proteins. Surf. Interfaces 2020, 20, 100558. [CrossRef]

22. Krishna, A.G.G.; Kumar, P.K.P. Physicochemical characteristics of commercial coconut oils produced in India. Grasas Aceites 2015, 66, e62. [CrossRef]

23. Yara-Varón, E.; Li, Y.; Balcells, M.; Canela-Garayoa, R.; Fabiano-Tixier, A.-S.; Chemat, F. Vegetable Oils as Alternative Solvents for Green Oleo-Extraction, Purification and Formulation of Food and Natural Products. Molecules 2017, 22, 1474. [CrossRef] [PubMed]

24. Li, Y.; Fabiano-Tixier, A.S.; Ruiz, K.; Castera, A.R.; Bauduin, P.; Diat, O.; Chemat, F. Comprehension of direct extraction of hydrophilic antioxidants using vegetable oils by polar paradox theory and small angle $\mathrm{X}$-ray scattering analysis. Food Chem. 2015, 173, 873-880. [CrossRef]

25. Barišić, V.; Flanjak, I.; Križić, I.; Jozinović, A.; Šubarić, D.; Babić, J.; Miličević, B.; Ačkar, Đ. Impact of high-voltage electric discharge treatment on cocoa shell phenolic components and methylxanthines. J. Food Process. Eng. 2019, 43, e13057. [CrossRef]

26. Barišić, V.; Flanjak, I.; Kopjar, M.; Benšić, M.; Jozinović, A.; Babić, J.; Šubarić, D.; Miličević, B.; Doko, K.; Jašić, M.; et al. Does High Voltage Electrical Discharge Treatment Induce Changes in Tannin and Fiber Properties of Cocoa Shell? Foods 2020, 9, 810. [CrossRef] [PubMed]

27. Zhang, M.; Vervoort, L.; Moalin, M.; Mommers, A.; Douny, C.; Hartog, G.J.D.; Haenen, G.R.M.M. The chemical reactivity of (-)-epicatechin quinone mainly resides in its B-ring. Free. Radic. Biol. Med. 2018, 124, 31-39. [CrossRef] [PubMed]

28. Totlani, V.M.; Peterson, D.G. Reactivity of Epicatechin in Aqueous Glycine and Glucose Maillard Reaction Models: Quenching of $\mathrm{C}_{2}, \mathrm{C}_{3}$, and $\mathrm{C}_{4}$ Sugar Fragments. J. Agric. Food Chem. 2005, 53, 4130-4135. [CrossRef]

29. Barišić, V.; Flanjak, I.; Tot, A.; Budeč, M.; Benšić, M.; Jozinović, A.; Babić, J.; Šubarić, D.; Miličević, B.; Ačkar, Đ. 5-Hydroxymethylfurfural and acrylamide content of cocoa shell treated with high voltage electrical discharge. Food Control. 2020, 110, 107043. [CrossRef]

30. De Oliveira, I.R.N.; Teófilo, R.F.; De Oliveira, E.B.; Ramos, A.M.; De Barros, F.A.R.; Maia, M.D.P.; Stringheta, P.C. Evaluation of potential interfering agents onin vitromethods for the determination of the antioxidant capacity in anthocyanin extracts. Int. J. Food Sci. Technol. 2016, 52, 511-518. [CrossRef]

31. Apak, R.;Özyürek, M.; Güçlü, K.; Çapanoğlu, E. Antioxidant Activity/Capacity Measurement. 1. Classification, Physicochemical Principles, Mechanisms, and Electron Transfer (ET)-Based Assays. J. Agric. Food Chem. 2016, 64, 997-1027. [CrossRef] 
32. Turkut, G.M.; Degirmenci, A.; Yildiz, O.; Can, Z.; Cavrar, S.; Karahalil, F.Y.; Kolaylı, S.; Kolaylı, S. Investigating 5-hydroxymethylfurfural formation kinetic and antioxidant activity in heat treated honey from different floral sources. J. Food Meas. Charact. 2018, 12, 2358-2365. [CrossRef]

33. Aam, E.; Mirghani, M.E.S.; Kh, M.; Na, K.; Mz, A. Challenges of Extraction Techniques of Natural Antioxidants and Their Potential Application Opportunities as Anti-Cancer Agents. Health Sci. J. 2018, 12, 596. [CrossRef]

34. Batista, N.N.; De Andrade, D.P.; Ramos, C.L.; Dias, D.R.; Schwan, R.F. Antioxidant capacity of cocoa beans and chocolate assessed by FTIR. Food Res. Int. 2016, 90, 313-319. [CrossRef]

35. Bordiga, M.; Locatelli, M.; Travaglia, F.; Coïsson, J.D.; Mazza, G.; Arlorio, M. Evaluation of the effect of processing on cocoa polyphenols: Antiradical activity, anthocyanins and procyanidins profiling from raw beans to chocolate. Int. J. Food Sci. Technol. 2015, 50, 840-848. [CrossRef]

36. Franco, R.; Oñatibia-Astibia, A.; Martínez-Pinilla, E. Health Benefits of Methylxanthines in Cacao and Chocolate. Nutrients 2013, 5, 4159-4173. [CrossRef]

37. Adamson, G.E.; Lazarus, S.A.; Mitchell, A.E.; Prior, R.L.; Cao, G.; Jacobs, P.H.; Kremers, B.G.; Hammerstone, J.F.; Rucker, R.B.; Ritter, K.A.; et al. HPLC Method for the Quantification of Procyanidins in Cocoa and Chocolate Samples and Correlation to Total Antioxidant Capacity. J. Agric. Food Chem. 1999, 47, 4184-4188. [CrossRef]

38. Singleton, V.L.; Orthofer, R.; Lamuela-Raventós, R.M. Analysis of total phenols and other oxidation substrates and antioxidants by means of folin-ciocalteu reagent. Methods Enzymol. 1999, 299, 152-178. [CrossRef]

39. Yang, J.; Meyres, K.J.; Van der Heide, J.; Liu, R.H. Varietal Differences in Phenolic Content and Antioxidant and Antiproliferative Activities of Onions. J. Agric. Food Chem. 2004, 52, 6787-6793. [CrossRef]

40. Benzie, I.F.F.; Strain, J.J. The ferric reducing ability of plasma (FRAP) as a measure of "antioxidant power": The FRAP assay. Anal. Biochem. 1996, 239, 70-76. [CrossRef]

Sample Availability: Samples of the chocolates are not available from the authors due to limited shelf-life.

Publisher's Note: MDPI stays neutral with regard to jurisdictional claims in published maps and institutional affiliations.

(C) 2020 by the authors. Licensee MDPI, Basel, Switzerland. This article is an open access article distributed under the terms and conditions of the Creative Commons Attribution (CC BY) license (http://creativecommons.org/licenses/by/4.0/). 